\title{
Peripheral Primary Neuroectodermal Tumour of the Ileum: A Case Report and Review of the Literature
}

\author{
Soukaina Harrak*, Siham Lemsanes, Sawsan Razine, Salma Najem, Khadija Benchekroun, \\ Saad Lannaz, Hind Mrabti, Hassan Errihani \\ Department of Medical Oncology, National Institute of Oncology, Rabat, Morocco \\ Email: *Soukaina.hrk@gmail.com
}

How to cite this paper: Harrak, S., Lemsanes, S., Razine, S., Najem, S., Benchekroun, K., Lannaz, S., Mrabti, H. and Errihani, H. (2021) Peripheral Primary Neuroectodermal Tumour of the Ileum: A Case Report and Review of the Literature. Journal of Cancer Therapy, 12, 399-408. https://doi.org/10.4236/jct.2021.127035

Received: May 19, 2021

Accepted: July 5, 2021

Published: July 8, 2021

Copyright (c) 2021 by author(s) and Scientific Research Publishing Inc. This work is licensed under the Creative Commons Attribution International License (CC BY 4.0).

http://creativecommons.org/licenses/by/4.0/

\begin{abstract}
Background: Ewing's Sarcoma (ES)/peripheral Primitive Neuroectodermal Tumor (pPNET) is a rare aggressive malignant small round cell tumour. Most of them arise in bony sites, and they represent the second commonest primary osseous malignancy in adolescence and young adults. The localization of the small bowel is very rare, to our knowledge only 35 cases of ES/pPNET of the small bowel have been reported in the literature. Case Presentation: We report a case of pPNET of the ileum in a 26-year-old female, presented abdominal pain with a transit disorder. The clinical examination was unremarkable. The histological and immunohistochemical study confirmed the diagnosis of peripheral primary neuroectodermal tumours. The patient was treated by tumor resection followed by adjuvant chemotherapy. The evolution was good, without recurrence with a follow-up of 12 months. Conclusion: PNET of the ileum is very rare. We report this case to enrich the database of this rare clinical entity and to improve the management of patients with PNET of the ileum.
\end{abstract}

\section{Keywords}

Ewing's Sarcoma, Primitive Neuroectodermal Tumor, Small Bowel Sarcoma, Extraosseous Sarcoma

\section{Introduction}

Peripheral primitive neuroectodermal tumors are small round cell neoplasms with neuroectodermal differentiation that develop outside the central and sympathetic nervous systems. These very rare tumors have the similar biochemical and oncogenic expression to several other tumors, such as Askin's tumor or 
Ewing's sarcoma, making them members of the Ewing's sarcomatous tumor family [1].

Although ES/PNET are primarily seen in bone and soft tissue in children and young adults, primitive visceral sites have also been reported such as the kidney, uterus, ovary, gallbladder, parotid gland, pancreas, lung, adrenal gland, esophagus and testicle [2] [3] [4] [5] [6]. Although it has been reported previously in this location [7] [8], ES/PNET is extremely rare in the small bowel.

Patients with ES/PNET tumors should be managed by multidisciplinary teams in or der to benefit from an optimal therapeutic strategy.

The present study reports a case of pPNET in the ileum in a 26-year-old woman, and describes the presenting symptoms, imaging findings, anatomopathological features of these tumors.

\section{Case Report}

A 26-year-old female patient, medical history was unremarkable, presented abdominal pain dating back to 3 months accompanied by alternating diarrhea and constipation evolving in a context of conservation of the general state. The abdominal examination on admission was normal, as was the rest of the physical examination.

Computed Tomography (CT) scanning of the abdomen revealed a $78 \times 60$ $\mathrm{mm}$ mass in the left lower abdominal compartment, the mass had a close contact with the left colon. Gastrointestinal Stromal Tumour (GIST) was suspected (Figure 1). Bone scintigrapphy and chest CT scan were unremarkable.

The patient underwent an exploratory laparotomy, and tumor resection was performed along with $40 \mathrm{~cm}$ of ileum. The specimen was sent for histopathological evaluation (Figure 2).

Macroscopic examination revealed a solid homogenous tumor mass measured $7 \times 5 \times 4 \mathrm{~cm}$, was found arising from the ileum, nodular greyish-white with foci of necrosis and hemorrhage. Microscopically, the tumor is made up of proliferation of small round and oval tumor cells with high mitosis. The tumor cells were arranged in the nest, possessing abundant eosinophilic cytoplasm. The tumor cell nuclei were round to oval with finely distributed chromatin and a small nucleolus. The foci of necrosis, hemorrhage, and edema within the tumor were noted. The surgical margins of the specimen were free of disease.

Immunohistochemically, the tumor cells showed diffuse membrane positivity for CD99, synaptophysin, and focal positivity for pancytokeratin and S-100. Tumour was negative for desmine, DOG-1, CD34, WT1, chromogranin, myogenin and OCT 4 . Ki 67 was 30\%. Overall the immunohistochemistry profile suggested the diagnosis of pPNET. The search for translocations had not been performed in our patient due to the unavailability of a molecular genetics platform in our hospital.

The postoperative course was unremarkable. The case was discussed in multidisciplinary meeting where it was decided to perform adjuvant chemotherapy based on Vincristine, Adriamycin, Cyclophosphamide (VAC) alternating with 

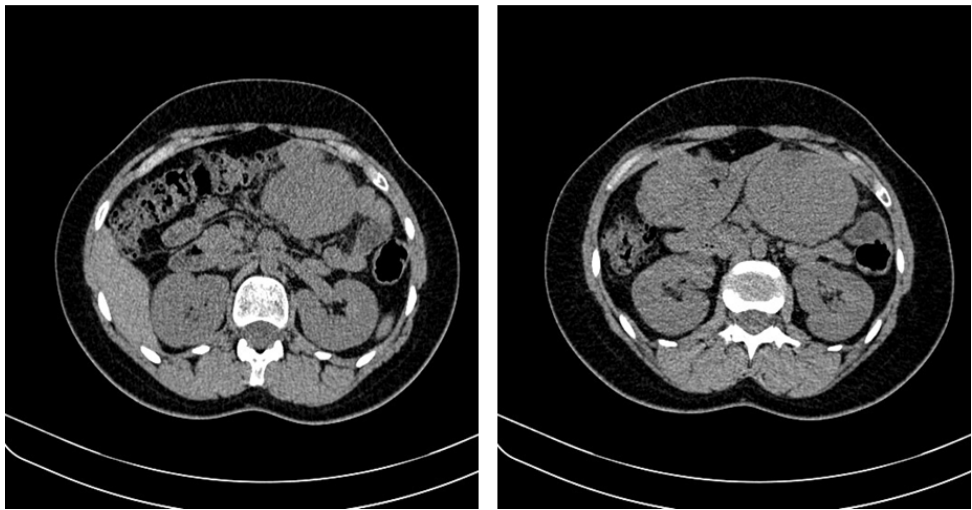

Figure 1. Computed tomography scan of the abdomen in axial section showing the ileal tumor process.
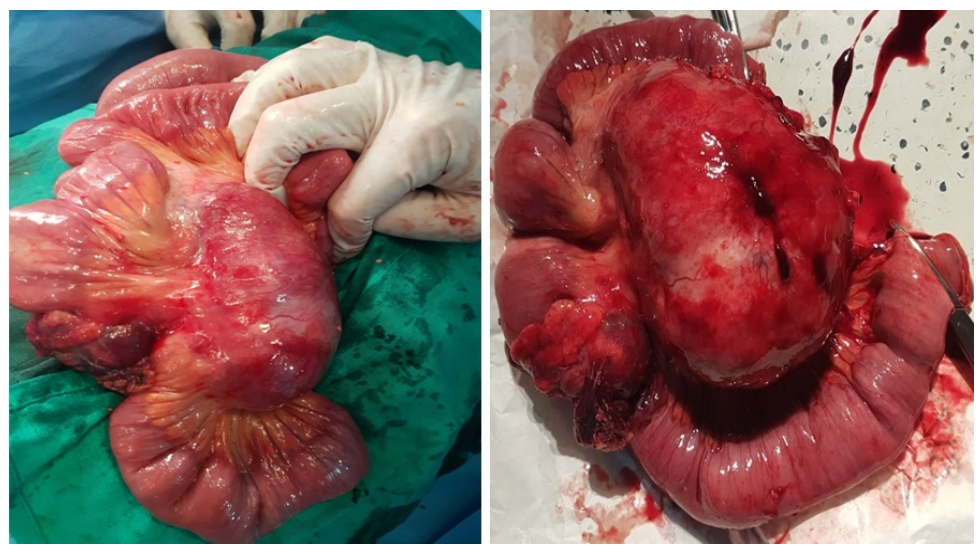

Figure 2. Operative image of the ileal resection.

Ifosfamide and Etoposide (IE). The patient received 6 cycles of chemotherapy with good tolerability. As the surgical procedure was considered curative, the radiotherapy supplement was not indicated.

She is currently alive 12 months after the chemotherapy, the clinical, biological and CT scanning examination did not show signs of recurrence.

\section{Discussion}

Ewing's tumors are malignant tumors characterized by small, round, blue cells that may show varying degrees of neuronal differentiation. Initially identified by James Ewing as being derived from endothelial cells, cytogenetic data showed that, in reality, this tumor was only an undifferentiated form of the neuroectodermal tumor family, and is currently referred to as the PNET tumor entity [9].

PNET/ES tumors are the second most common cause of malignant bone tumors in adolescents and young adults. These tumors mainly affect bone but can also be purely extraosseous in soft tissue [10] [11]. More rarely, visceral sites including the pancreas, liver, adrenal gland, esophagus, uterus, gastrointestinal tract, heart, kidneys, ovaries, testes, bladder and parotid gland have been described [12] [13] [14]. ES/PNETs of the small intestine are rare, to date only 35 cases have been reported in the literature (Table 1). 
Table 1. Cases of ES/pPNET of the small bowel, reported in the literature to date.

\begin{tabular}{|c|c|c|c|c|c|c|}
\hline Reference & Age/sexe & Localisation & $\begin{array}{c}\text { Clinical } \\
\text { presentation }\end{array}$ & Treatment & $\begin{array}{c}\text { Metastasis } \\
\text { ondiagnosis }\end{array}$ & Survival \\
\hline Hori and Kato 2000 [15]. & $40 / \mathrm{M}$ & Jejunum & Intestinal perforation & Surgery/CMT & ND & 5 \\
\hline Sarangarajna, et al. 2001 [16]. & $13 / \mathrm{M}$ & Jejunum & Occlusion & Surgery & Absent & 12 NID \\
\hline Shek, et al. 2001 [17]. & $9 / \mathrm{F}$ & Small bowel & Abdominal distension & Surgery/CMT & Pelvis & 25 \\
\hline Adair, et al. [7]. & $21 / \mathrm{f}$ & Duodenum & Surgery/CMT & ND & & $10 \mathrm{NID}$ \\
\hline Graham, et al. 2002 [18]. & $14 / \mathrm{M}$ & Ileum & Anemia & Surgery/CMT & ND & $52 \mathrm{NID}$ \\
\hline Balasubramanian, et al. 2002 [19]. & $53 / \mathrm{F}$ & Ileum & Abdominal Mass & Surgery & ND & ND \\
\hline Kie, et al. 2003 [20]. & $20 / \mathrm{F}$ & Duodenum & ulcer & Surgery/CMT & & $18 \mathrm{NID}$ \\
\hline Boehm, et al. 2003 [21]. & $18 / \mathrm{M}$ & Ileum & Occlusion & Surgery/CMT & Peritoneum & ND \\
\hline Bala, et al. 2006 [22]. & $57 / \mathrm{F}$ & Ileum & Mass & Surgery/CMT & ND & 8 NID \\
\hline Batzioui, et al. 2006 [23]. & $66 / M$ & Small bowel & & Surgery/CMT & ND & 48 NID \\
\hline Kim, et al. 2007 [24]. & $63 / \mathrm{M}$ & Ileum & Occlusion & Surgery/CMT & Lymph nodes & ND \\
\hline Sethi and Smith 2007 [25]. & $44 / \mathrm{M}$ & Ileum & Occlusion & Surgery/CMT & ND & 13 \\
\hline Rodarte-Shade, et al. 2012 [26]. & $32 / \mathrm{M}$ & Ileum & Anemia & Surgery/CMT & Absent & $6 \mathrm{NID}$ \\
\hline Vignali, et al. 2012 [8]. & $15 / \mathrm{F}$ & Ileum & Mass & Surgery/CMT & ND & ND \\
\hline Prasertvit, Stoikes 2013 [27]. & $28 / \mathrm{F}$ & Small bowel & ND & ND & ND & ND \\
\hline Kim, et al. 2013 [28]. & $23 / \mathrm{M}$ & Jejunum & $\begin{array}{c}\text { Tumor rupture } \\
\text { without perforation }\end{array}$ & Surgery/CMT & $\begin{array}{c}\text { Liver and lymph } \\
\text { nodes }\end{array}$ & ND \\
\hline Rachan Shetty 2014 [29]. & $24 / \mathrm{M}$ & Ileum & Occlusion & Surgery/CMT & ND & 15 NID \\
\hline Milione, et al. 2014 [30]. & $18 / \mathrm{M}$ & Ileum & Liver metastasis & ND & Liver & 8 \\
\hline Milione, et al. 2014 [30]. & $20 / M$ & Ileum & Liver metastasis & ND & Liver & 28 \\
\hline Milione, et al. 2014 [30]. & $42 / \mathrm{M}$ & Ileum & ND & Surgery/CMT & absent & 11 \\
\hline Milione, et al. 2014 [30]. & $45 / \mathrm{M}$ & Ileum & ND & Surgery/CMT & absent & 13 \\
\hline Milione, et al. 2014 [30]. & $15 / \mathrm{F}$ & Ileum & ND & Surgery CMT/RTH & absent & 28 \\
\hline Milione, et al. 2014 [30]. & $57 / \mathrm{M}$ & Ileum & ND & Surgery & absent & ND \\
\hline Milione, et al. 2014 [30]. & $28 / \mathrm{F}$ & Ileum & & Surgery & Liver & 204 NID \\
\hline Padma, et al. 2015 [31]. & $22 / \mathrm{F}$ & Jejunum & Mass & Surgery & absent & ND \\
\hline Peng, et al. 2015 [32]. & $59 / \mathrm{M}$ & Ileum & Abdominal pain & Surgery & ND & ND \\
\hline Peng, et al. 2015 [32]. & $22 / \mathrm{M}$ & Ileocecum & Mass & Surgery & Liver & ND \\
\hline Peng, et al. 2015 [32]. & $36 / \mathrm{F}$ & Ileocecum & Mass & Surgery/CMT & ND & 34 \\
\hline Liu, et al. 2016 [33]. & $15 / M$ & Jejunum & $\begin{array}{l}\text { Hematemesis, } \\
\text { Melena, anemia }\end{array}$ & Surgery & ND & 7 \\
\hline $\mathrm{Li}$, et al. 2017 [34]. & $16 / \mathrm{F}$ & Ileum & Anemia & Surgery & ND & 10 NID \\
\hline Kim, et al. 2017 [35]. & $9 / \mathrm{F}$ & Jejunum & Anemia & Surgery/CMT & Peritoneum & ND \\
\hline Liao, et al. 2018 [36]. & $25 / \mathrm{F}$ & Ileum & Mass & Surgery & ND & $\mathrm{ND}$ \\
\hline Cantu, et al. 2019 [37]. & $67 / \mathrm{F}$ & Jejunum & $\begin{array}{l}\text { Abdominal pain } \\
+ \text { constipation }\end{array}$ & Surgery & absent & 3 NID. \\
\hline Yagnik, et al. 2019 [38]. & $42 / \mathrm{M}$ & Jejunum & perforation & Surgery/CMT & ND & 9 NID \\
\hline Andrej, et al. 2020 [39]. & $30 / \mathrm{F}$ & Jejunum & asthenia & Surgery & absent & 2 \\
\hline Our case & $26 / \mathrm{F}$ & Ileum & $\begin{array}{l}\text { Abdominal pain, } \\
\text { transit disorder }\end{array}$ & Surgery/CMT & absent & $\begin{array}{l}\text { No recurrence } \\
\text { at } 12 \text { month. }\end{array}$ \\
\hline
\end{tabular}

M: Male; F: female; CMT: chemotherapy, RTH: radiotherapy, ND: not documented; NID: No information of death. 
Among the reported cases, including our case, there were 19 males and $17 \mathrm{fe}-$ males. The mean age of the patients at diagnosis was 31 years for both sexes, with extremes ranging from 9 years to 67 years. The most frequent location in the small bowel was: ileum in 22 cases followed by jejunum in 9 cases followed by duodenum in 2 cases, in 3 cases the exact location in the small bowel was unspecified.

The clinical symtomatology is poor, dominated by locoregional signs related to the mass syndrome (pain, palpable mass) [8] [19] [22] [31] [32] [36]. Complications such as occlusion, perforation or rupture may occur [15] [16] [21] [24] [25] [28] [38]. Ileal PNET may be revealed by metastasis in advanced stages of the disease [30]. In the cases reported the most frequent metastatic location was in the liver.

Imaging examination such as CT scan can provide important information regarding the size of the mass, involvement of adjacent structures, and the presence of metastasis. However, there are no specific radiologic signs of PNET. For this reason, Ewing's sarcoma can initially be treated as a malignant gastrointestinal stromal tumor [22]-[34].

Diagnosis is always based on histological analysis and immunohistochemical study, supplemented or not by cytogenetic study.

Macroscopically, the tumor is rounded, oval or multi-nodular, well-limited, without encapsulation. When cut, it is grey-beige or yellow and its consistency is soft or friable. Necrotic or hemorrhagic reshaping is frequent. Calcifications are sometimes observed [40].

Histology shows a malignant proliferation of pseudo-alveolar or diffuse lobular architecture, consisting of small round or oval cells with monomorphic and poorly differentiated appearance. Occasionally, neural differentiation elements such as Flexner-Winsersteiner rosettes or Homer-Wright pseudo-rosettes are present. These elements indicate neuroectodermal origin, but their absence does not exclude diagnosis [41].

The differential diagnosis is first made with other round cell tumors: GIST, lymphoma, desmoplastic small round cell tumor and rhabdomyosarcoma. In this case, our patient was initially diagnosed with GIST due to clinical symptoms and imaging results.

Immunohistochemistry is of great help in distinguishing between these different tumor entities. Almost all Ewing/PNET tumors are positive for anti-CD99 antibody. However, it is not specific at all: CD99 membrane positivity is classical in lymphoblastic lymphomas, in very rare extramedullary myeloid tumors, in poorly differentiated round cell synovialosarcomas, desmoplastic tumors, and alveolar rhabdomyosarcomas are CD99+ [42]. Neuroectodermal markers are variably expressed and can be demonstrated in immunohistochemistry by the positivity of NSE, LEU7, synaptophysin, chromogranin, S100, and GFAP antibody. It is important to be aware of the possibility of labelling with anti-pankeratin AE1/AE3 antibody in about 25\% of cases [43]. Desmin is exceptionally expressed 
[44].

Two types of translocations predominate: translocations combine the N-terminal region of the EWS gene of chromosome 22 with the C-terminal region of a gene comprising the ETS sequence (FLI1 gene of chromosome 11 in $85 \%$ of cases or ERG of chromosome 21 in $10 \%$ of cases). Rarer translocations have been described as $\mathrm{t}(7 ; 22), \mathrm{t}(17,2), \mathrm{t}(2,22)$ translocations. These translocations are a true genetic marker of the PNET/Ewing entity [45].

In the absence of a therapeutic consensus on these exceptional tumors, the treatment remains the same as that proposed in other Ewing sarcoma localizations. The treatment of these tumors is based on a multimodal treatment combining local surgery and/or radiotherapy followed by multidrug systemic chemotherapy [31] [32] [33] [34]. Current chemotherapy regimens include combinations of vincristine, cyclophosphamide and doxorubicin [32]. The addition of ifosfamide and etoposide to a standard regimen significantly improves the outcome for patients with non metastatic Ewing's sarcoma a [45].

The prognosis remains difficult to predict due to the small number of reported cases and the lack of follow-up.

\section{Conclusions}

PNET of the ileum is an exceptional extraosseous malignant tumor. The therapeutic challenge of this disease is to ensure both systemic and local disease control.

The current treatment of these tumors is based on a multimodal treatment combining systemic chemotherapy, surgery and radiotherapy.

The prognosis is largely conditioned by the metastatic or localized stage.

\section{Authors' Contributions}

All authors have been involved in the process of writing and have approved the final manuscript.

\section{Conflicts of Interest}

The authors declare that they have no competing interests.

\section{References}

[1] O’Sullivan, M.J., Perlman, E.J., Furman, J., Humphrey, P.A., Dehner, L.P. and Pfeifer, J.D. (2001) Visceral Primitive Peripheral Neuroectodermal Tumors: A Clnicopathologic and Molecular Study. Human Pathology, 32, 1109-1115. https://doi.org/10.1053/hupa.2001.28247

[2] Deb, R.A., Desai, S.B., Amonkar, P.P., Aiyer, P.M. and Borges, A.M. (1998) Primary Primitive Neuroectodermal Tumour of the Parotid Gland. Histopathology, 33, 375-378. https://doi.org/10.1046/j.1365-2559.1998.00535.x

[3] Kim, K.J., Jang, B.W., Lee, S.K., Kim, B.K. and Nam, S.L. (2004) A Case of Pepipheral Primitive Neumsotoderrnal Tumor of the Ovar. International Journal of Gynecological Cancer, 14, 370-372.

https://doi.org/10.1136/ijgc-00009577-200403000-00027 
[4] Kuroda, M., Urano, M., Abe, M., Mizoguchi, Y., Horibe, Y., Murakami, M., Tashiro, K., et al. (2000) Primary Primitive Neuroectodermal Tumour of the Kidney. Pathology International, 50, 967-972. https://doi.org/10.1046/j.1440-1827.2000.01147.x

[5] Jhon, L.B., Sánchez-Fayos, P., Relloso, M.J.M., Barón, D.C. and Cubero, J.C.P. (2019) Primitive Neuroectodermal Tumor of the Esophagus with Metastasis in the Pineal Gland. Endoscopy International Open, 7, E1163-E1165. https://doi.org/10.1055/a-0977-2614

[6] Daniel, C., Laurence, V. and Pierga J.Y. (2013) Tumeur Neuroectodermique Primitive périphé rique dupoumon chez un homme de 49 ans. Revue des Maladies Respiratoires, 30, 62-66. https://doi.org/10.1016/j.rmr.2012.09.016

[7] Adair, A., Harris, S.A., Coppen, M.J. and Hurley, P.R. (2001) Extraskeletal Ewings Sarcoma of the Small Bowel: Case Report and Literature Review. Journal of the Royal College of Surgeons of Edinburgh, 46, 372-374.

[8] Vignali, M., Zacche, M.M., Messori, P., Natale, A. and Busacca, M. (2012) Ewing's Sarcoma of the Small Intestine Misdiagnosed as a Voluminous Pedunculated Uterine Leiomyoma. European Journal of Obstetrics \& Gynecology and Reproductive Biology, 162, 234-235. https://doi.org/10.1016/j.ejogrb.2012.02.009

[9] Marec-Bérard, P., Chotel, F. and Claude, L. (2010) Tumeurs PNET/Ewing: Prise en charge actuelle et pe perspectives. Bulletin du Cancer, 97, 707-713.

[10] Ahmad, R., Mayol, B.R., Davis, M. and Rougraff, B.T. (1999) Extraskeletal Ewing's Sarcoma. Cancer, 85, 725-731.

https://doi.org/10.1002/(SICI)1097-0142(19990201)85:3<725::AID-CNCR23>3.0.C $\underline{\mathrm{O} ; 2-2}$

[11] Rud, N.P., Reiman, H.M., Pritchard, D.J., Frassica, F.J. and Smithson, W.A. (1989) Extraosseous Ewing's Sarcoma. A Study of 42 Cases. Cancer, 64, 1548-1553. https://doi.org/10.1002/1097-0142(19891001)64:7<1548::AID-CNCR2820640733>3. $\underline{0 . \mathrm{CO} ; 2-\mathrm{W}}$

[12] Jimenez, R.E., Folpe, A.L., Lapham, R.L., Ro, J.W., O’Shea, P.A., Weiss, S.W. and Amin, M.B. (2002) Primary Ewing's Sarcoma/Primitive Neuroectodermal Tumor of the Kidney: A Clinicopathologic and Immunohistochemical Analysis of 11 Cases. The American Journal of Surgical Pathology, 26, 320-327. https://doi.org/10.1097/00000478-200203000-00005

[13] Abi-Raad, R., Manetti, G.J., Colberg, J.W., Hornick, J.L., Shah, J.G. and Prasad, M.L. (2013) Ewing Sarcoma/Primitive Neuroectodermal Tumor Arising in the Adrenal Gland. Pathology International, 63, 283-286. https://doi.org/10.1111/pin.12063

[14] Javery, O., Krajewski, K., O’Regan, K., Bela, K., Giardino, A., Jagannathan, J. and Ramaiya, N.H. (2011) A to Z of Extraskeletal Ewing Sarcoma Family of Tumors in Adults: Imaging Features of Primary Disease, Metastatic Patterns, and Treatment Responses. American Journal of Roentgenology, 197, W1015-W1022. https://doi.org/10.2214/AJR.11.6667

[15] Horie, Y. and Kato, M. (2000) Peripheral Primitive Neuroectodermal Tumor of the Small Bowel Mesentery: A Case Showing Perforation at Onset. Pathology International, 50, 398-403.

[16] Sarangarajan, R., Hill, D.A., Humphrey, P.A., Hitchcock, M.G., Dehner, L.P. and Pfeifer, J.D. (2001) Primitive Neuroectodermal Tumors of the Biliary and Gastrointestinal Tracts: Clinicopathologic and Molecular Diagnostic Study of Two Cases. Pediatric and Developmental Pathology, 4, 185-191. https://doi.org/10.1007/s100240010141 
[17] Shek, T.W., Chan, G.C., Khong, P.L., Chung, L.P. and Cheung, A.N. (2001) Ewing Sarcoma of the Small Intestine. Journal of Pediatric HematologylOncology, 23, 530-532. https://doi.org/10.1097/00043426-200111000-00013

[18] Graham, D.K., Stork, L.C., Wei, Q., Ingram, J.D., Karrer, F.M., Mierau, G.W., et al. (2002) Molecular Genetic Analysis of a Small Bowel Primitive Neuroectodermal Tumor. Pediatric and Developmental Pathology, 5, 86. https://doi.org/10.1007/s10024-001-0192-1

[19] Balasubramanian, B., Dinakarababu, E. and Molyneux, A.J. (2002) Primary Primitive Neuroectodermal Tumour of the Small Bowel Mesentery: Case Report. European Journal of Surgical Oncology, 28, 197-198. https://doi.org/10.1053/ejso.2001.1155

[20] Kie, J.H., Lee, M.K., Kim, C.J., Lee, K., Kwon, K.W. and Yang, W.I. (2003) Primary Ewing's Sarcoma of the Duodenum: A Case Report. International Journal of Surgical Pathology, 11, 331-337. https://doi.org/10.1177/106689690301100416

[21] Boehm, R., Til, H., Landes, J., Schmid, I. and Joppich, I. (2003) Ileoileal Intussusception Caused by a Ewing Sarcoma Tumour. An Unusual Case Report. European Journal of Pediatric Surgery, 13, 272-275. https://doi.org/10.1055/s-2003-42234

[22] Bala, M., Maly, A., Remo, N., Gimmon, Z. and Almogy, G. (2006) Peripheral Primitive Neuroectodermal Tumor of Bowel Mesentery in Adults. The Israel Medical Association Journal, 8, 515-516.

[23] Batziou, C., Stathopoulos, G.P., Petraki, K., Papadimitriou, C., Rigatos, S.K., Kondopodis, E. and Batzios, S. (2006) Primitive Neurectodermal Tumors: A Case of Extraosseous Ewing's Sarcoma of the Small Intestine and Review of the Literature. Journal of BUON, 11, 519-522.

[24] Kim, D.W., Chang, H.J., Jeong, J.Y., Lim, S.B., Lee, J.C., Hong, E.K., Lee, G.K., et al. (2007) Ewing's Sarcoma/Primitive Neuroectodermal Tumor (ES/PNET) of the Small Bowel: A Rare Cause of Intestinal Obstruction. International Journal of Colorectal Disease, 22, 1137-1138. https://doi.org/10.1007/s00384-006-0142-5

[25] Sethi, B. and Smith, G.T. (2007) Primary Primitive Neuroectodermal Tumour Arising in the Small Bowel. Histopathology, 50, 665-666.

https://doi.org/10.1111/j.1365-2559.2007.02631.x

[26] Rodarte-Shade, M., Palomo-Hoil, R., Vazquez, J., Ancer, A., Flores-Gutierrez, J.P., et al. (2012) Primitive Neuroectodermal Tumor (PNET) of the Small Bowel in a Young Adult with Lower Gastrointestinal Bleeding. Journal of Gastrointestinal Cancer, 43, S243-S245. https://doi.org/10.1007/s12029-012-9409-y

[27] Prasertvit, S. and Stoikes, N. (2013) A Rare Case of Ewing's Sarcoma of the Small Intestine. The American Surgeon, 79, E78-E79.

https://doi.org/10.1177/000313481307900212

[28] Kim, J.M., Chu, Y.C., Choi, C.H., Kim, L., Choi, S.J., Park, I.S., Han, J.Y., et al. (2013) Peripheral Primitive Neuroectodermal Tumor with Osseous Component of the Small Bowel Mesentery: A Case Study. Korean Journal of Pathology, 47, 77-81. https://doi.org/10.4132/KoreanJPathol.2013.47.1.77

[29] Rachan Shetty, K.S., Naveen, J.A., Premalatha, C.S. and Lakshmaiah, K.C. (2014) Peripheral Primitive Neuroectodermal Tumor of Small Bowel Mesentry Presenting as Intestinal Obstruction: A Case Report. Austral-Asian Journal of Cancer, 13, 125.

[30] Milione, M., Gasparini, P., Sozzi, G., Mazzaferro, V., Ferrari, A., Casali, P.G., Perrone, F., et al. (2014) Ewing Sarcoma of the Small Bowel: A Study of Seven Cases, Including One with the Uncommonly Reported EWSR1-FEV Translocation. Histopathology, 6425, 1014-1026. https://doi.org/10.1111/his.12350 
[31] Padma, M., Lakshmi, R.R. and Kumar, C.K. (2015) Extraskeletal Ewing's Sarcoma of the Small Bowel. International Journal of Medical Science and Clinical Invention, 2, 645-647.

[32] Peng, L., Yang, L., Wu, N. and Wu, B.O. (2015) Primary Primitive Neuroectodermal Tumor Arising in the Mesentery and Ileocecum: A Report of Three Cases and Review of the Literature. Experimental and Therapeutic Medicine, 9, 1299-1303. https://doi.org/10.3892/etm.2015.2242

[33] Liu, Z., Xu, Y.H., Ge, C.L., Long, J., Du, R.X. and Guo, K.J. (2016) Huge Peripheral Primitive Neuroectodermal Tumor of the Small Bowel Mesentery at Nonage: A Case Report and Review of the Literature. World Journal of Clinical Cases, 4, 306-309. https://doi.org/10.12998/wjcc.v4.i9.306

[34] Li, T., Zhang, F., Cao, Y., Ning, S., Bi, Y., Xue, W. and Ren, L. (2017) Primary Ewing's Sarcoma/Primitive Neuroectodermal Tumor of the Ileum: Case Report of a 16-Year-Old Chinese Female and Literature Review. Diagnostic Pathology, 12, 37. https://doi.org/10.1186/s13000-017-0626-3

[35] Kim, Y.S., Moon, H.M., Lee, K.S., Park, Y.S., Kim, H.Y., Kim, J.Y., Cho, J.M., et al. (2017) Pediatric Ewing's Sarcoma/Primitive Neuroectodermal Tumor (ES/PNET) Developed in the Small Intestine: A Case Report. Clinical Pediatric Hematology-Oncology, 24, 162. https://doi.org/10.15264/cpho.2017.24.2.162

[36] Liao, Y.S., Chiang, I.H. and Gao, H.W. (2018) A Mesenteric Primary Peripheral Ewing's Sarcoma/Primitive Neuroectodermal Tumor with Molecular Cytogenetic Analysis: Report of a Rare Case and Review of Literature. Indian Journal of Pathology \& Microbiology, 61, 248-251. https://doi.org/10.4103/IJPM.IJPM 54617

[37] Cantu, C., Bressler, E., Dermawan, J. and Paral, K. (2019) Extraskeletal Ewing Sarcoma of the Jejunum: A Case Report. The Permanente Journal, 23, 18-255.

[38] Yagnik, V.D. and Dawka, S. (2019) Extraskeletal Ewing's Sarcoma/Peripheral Primitive Neuroecto Dermal Tumor of the Small Bowel Presenting with Gastrointestinal Perforation. Clinical and Experimental Gastroenterology, 12, 279-285. https://doi.org/10.2147/CEG.S203697

[39] Kolosov, A., Dulskas, A., Pauza, K., Selichova, V., Seinin, D. and Stratilatovas, E. (2020) Primary Ewing's Sarcoma in a Small Intestine-A Case Report and Review of the Literature. BMC Surgery, 20, 113. https://doi.org/10.1186/s12893-020-00774-Z

[40] Franchi, A., Pasquinelli, G., Cenacchi, G., Della Rocca, C., Gambini, C., Bisceglia, M., Martinelli, G.N., et al. (2001) Immunohistochemical and Ultrastructural Investigation of Neural Differentiation in Ewing Sarcoma/PNET of Bone and Soft Tissues. Ultrastructural Pathology, 25, 219-225. https://doi.org/10.1080/019131201300343856

[41] Vigouroux, V., Jeanne, C., Comoz, F., Auriault, M.L., Bottet, P. and Bensadoun, H. (1998) Tumeur neuroectodermique primitive (PNET) rénale. A propos d'un cas. Progrès en Urologie, 8, 392-397.

[42] Folpe, A.L., Hill, C.E., Parham, D.M., O’Shea, P.A. and Weiss, S.W. (2000) Immunohistochemical Detection of FLI-1 Protein Expression: A Study of 132 Round Cell Tumors with Emphasis on CD99-Positive Mimics of Ewing's Sarcoma/Primitive Neuroectodermal Tumor. The American Journal of Surgical Pathology, 24, 1657-1662. https://doi.org/10.1097/00000478-200012000-00010

[43] Gu, M., Antonescu, C.R., Guiter, G., Huvos, A.G., Ladanyi, M. and Zakowski, M.F. (2000) Cytoke Ratin Immunoreactivity in Ewing's Sarcoma: Prevalence in 50 Cases Confirmed by Molecular Diagnostic Studies. The American Journal of Surgical Pathology, 24, 410-416. https://doi.org/10.1097/00000478-200003000-00010 
[44] Folpe, A.L., Goldblum, J.R., Rubin, B.P., Shehata, B.M., Liu, W., Dei Tos, A.P. and Weiss, S.W. (2005) Morphologic and Immunophenotypic Diversity in Ewing Family Tumors: A Study of 66 Genetically Confirmed Cases. The American Journal of Surgical Pathology, 29, 1025-1033.

https://doi.org/10.1097/01.pas.0000167056.13614.62

[45] Ordonez, J.L., Osuna, D., Herrero, D., Álava, E.D. and Madoz-Gúrpide, J. (2009) Advances in Ewing's Sarcoma Research: Where Are We Now and What Lies Ahead? Cancer Research, 69, 7140-7150.

https://doi.org/10.1158/0008-5472.CAN-08-4041 